\title{
Meta-analysis of Response inhibition in Juvenile Myoclonic Epilepsy
}

\author{
Anna Smith $\mathrm{PhD}^{1}$, Marte Syvertsen ${ }^{5,6}$, Deb K Pal ${ }^{1,2,3,4}$
}

\footnotetext{
${ }^{1}$ Department of Basic and Clinical Neuroscience, Institute of Psychiatry, Psychology \& Neuroscience, King's College London, London, United Kingdom

${ }^{2}$ MRC Centre for Neurodevelopmental Disorders, King's College London, London, United Kingdom

${ }^{3}$ King's College Hospital, London, UK

${ }^{4}$ Evelina London Children's Hospital, London UK

${ }^{5}$ Department of Neurology, Drammen Hospital, Vestre Viken Hospital Trust, Drammen, Norway

6Institute of Clinical Medicine, University of Oslo, Oslo, Norway

Corresponding author:

Anna Smith

Department of Basic and Clinical Neuroscience

Institute of Psychiatry, Psychology and Neuroscience

Kings College London

125 Coldharbour Lane

London SE5 9NU

anna.smith@kcl.ac.uk
} 


\section{Abstract}

Background. Patients with Juvenile Myoclonic Epilepsy (JME) show evidence of cognitive impulsivity that may be linked to later adverse psychosocial outcomes. Here we quantify the strength of association and estimate effect size of response inhibition by pooling available evidence in a metaanalysis.

Methods. We conducted a systematic review of the literature using Ovid MEDLINE and Ovid EMBASE databases (covering 2001-2019) with a search strategy using combinations of the specific Medical Subject Headings (MeSH) terms 'juvenile myoclonic epilepsy, cognitive impulsivity, response inhibition, Stroop, cognition, personality, traits' using the 'explode' feature where possible. We also searched within references of retrieved articles. We included studies reporting effect sizes describing established measures of response inhibition in teenage and adult patients with Juvenile Myoclonic Epilepsy.

Results. Using the effect sizes pooled from 16 studies comprising 1047 patients and controls, we found effect sizes for response inhibition to be homogeneous with a significant moderate mean effect size of $d=0.50$ (95\% Cl: 0.37-0.63).

Conclusions. We confirm that reduced response inhibition is a consistently observed homogeneous trait in patients with JME. 


\section{Introduction}

Juvenile myoclonic epilepsy (JME) is a common adolescent-onset subtype of genetic generalised epilepsy (GGE). In his original descriptions of JME or "impulsive petit mal”, Janz alluded to a set of clinical observations, including "an attractive but emotionally unstable and unreliable personality, which is rather immature and oscillates between friendliness and mistrust...tending to cause problems where social adaptation is concerned" (1). This description alongside other clinical observations formed the basis for the so-called JME personality, which, when transposed onto a psychiatric framework, was subsequently associated with DSM borderline personality or Cluster B disorder $(2,3)$. Convergent evidence from neuropsychological and neuroimaging studies strongly suggests deficits in executive function (EF) and impulsivity among JME patients (4-8) and these may underpin the observed personality traits and reported clinical observations. These EF deficits are not specific for JME and up to $30 \%$ of young people with epilepsy may have clinically significant EF deficits $(9,10)$.

EF refers to a set of cognitive processes involved in planning, monitoring, and goal-directed behaviour, which include response inhibition, working memory, and mental set-shifting (11) and may also encompass attentional control and planning (12). Strong executive function is associated with healthy behaviours such as physical activity, healthy eating, and treatment adherence, and is negatively associated with unhealthy behaviours such as smoking, drinking alcohol, eating junk foods and obesity (13-16). EF may therefore significantly impact on the health behaviours and long-term outcomes of youth with epilepsy or other long-term conditions.

An extensive review of cognitive functioning including EF in JME and other GGEs found a moderate mean effect size (ES) of $d=0.72$ for EF with evidence for substantial heterogeneity ( $70 \%$ of the observed variance was thought to be attributable to heterogeneity) (17). This heterogeneity might be explained by the diverse processes involved in EF (vide supra) and we therefore hypothesise more homogeneous effects may be observable if EF processes are studied separately or if moderators are considered $(11,12)$. Response inhibition is the obvious of the several EF processes to study, since it is thought to be the cognitive analogue of impulsive behavior and most EF studies in epilepsy have measured it $(4,5,18)$. Moreover, response inhibition may represent a useful biomarker for psychosocial prognosis or even an endophenotype for genetic analysis. Biomarkers may be particularly important for identifying those patients at risk of adverse long-term outcomes that are possibly influenced by early manifesting personality or cognitive traits (19-21). Likewise, endophenotypes are important for gene discovery in GGE and for testing hypotheses of shared 
aetiology across neuropsychiatric phenotypes where EF deficits are observed (eg autism, addiction and ADHD and many others (22)).

The aim of this study was to investigate evidence for impaired response inhibition in JME and identify its potential moderators through meta-analysis of published studies. We hypothesised a moderate, homogenous mean effect size for response inhibition across JME studies in comparison to the heterogeneity in effect size seen for EF in general.

\section{Methods}

We carried out a literature search to identify published studies where cognitive impulsivity (which includes both response inhibition and decision-making) had been measured in patients with JME, following the guidelines of the Meta-analysis of Observational Studies in Epidemiology (MOOSE) Group (23). We searched MEDLINE and PsycINFO from January 2001 until November 2019 using combinations of the specific Medical Subject Headings (MeSH) terms 'juvenile myoclonic epilepsy' together with the keywords, "cognitive impulsivity, response inhibition, Stroop, cognition, impulsivity, personality, traits" and using the 'explode' feature where possible. We looked through the reference sections of all retrieved articles for additional sources of data. We did not define an age criterion. To avoid 'file-drawer effects', whereby studies with small effect sizes and therefore non-significant findings remain unpublished, we contacted research teams for primary data. We also carried out a quality assessment (QA) of each paper using the Newcastle-Ottawa Assessment Scale for Case Control Studies (24) and although we did not exclude papers on the basis of their QA score, we considered the score as a potential predictor of effect size. This QA scale consists of eight items with three subscales and a maximum score of nine. Conventionally, a study with a score exceeding seven is considered of good quality.

\section{Inclusion criteria}

To minimize risk of bias we set out a priori inclusion criteria: (a) use of the Stroop Task to measure cognitive impulsivity. Response inhibition is primarily measured by Go/NoGo and Stop-signal tasks. The decision to restrict inclusion to the Stroop Task derives from the recognised differences in concurrent validity and factor structure between instruments assessing response inhibition. The Go/NoGo task requires participants to respond to one set of stimuli and to not respond to another set of stimuli and the Stroop task is the example that has been most commonly used in JME studies. The Stroop task assesses an individual's ability to inhibit interference from an automatic 'hard-wired' response and provides an index of inhibition failure, or commission errors. Individuals are required to name the colour of a printed word while ignoring interference from the word itself: naming the colour of the word takes longer and is more prone to errors when the name and colour are 
mismatched (incongruent) than when the colour of the ink matches the name of the colour (congruent). (b) a diagnosis of JME based upon the presence of myoclonic jerks, together with a consistent EEG profile with a normal background and no additional neurological condition (with the exception of childhood absence epilepsy (CAE)) (25). (c) an IQ greater than 70 for all participants; (d) The data had to be presented in a form which allowed calculation of an effect size. We included studies with healthy comparison groups but, to increase the number of available research papers, we also included studies comparing patients on standardized measures using normative data.

\section{Exclusion criteria}

(a) Data published in abstract only; (b) Articles published before 2000; (c) Articles in non peerreviewed journals.

\section{Data abstraction}

For all studies, we tabulated the following information where available: year of publication and country from which samples were selected (Table 1). For both patient and comparison groups, we reported sample size, age (in months), mean IQ scores, sex ratio and quality rating of the study. For the patient group only, we tabulated percentages who were on poly-, mono-therapy, or medication free, mean age of onset and duration of epilepsy as well as seizure frequency (see Table 1).

Where research groups had multiple publications, only one publication was selected to prevent repetition of data unless it could be confirmed that effect sizes were derived from a different sample. Where a decision between two papers needed to be made this was based on the amount of information reported in the publication in order to enhance further analysis.

\section{Analysis}

Effect sizes were calculated using Cohen's $d$ values (26), (see (A) within Equation panel below), to describe the difference in performance between patients and comparison group or population norms for response inhibition. The two standard deviations from each sample were pooled using equation (B). An unbiased estimate of $d$ was then acquired using the equation (C).

Effect size $(d)=$ Mean of experimental group-Mean of comparison group

Standard deviation

$$
\mathrm{SD}_{\text {pooled }}=\sqrt{\frac{\left(N_{E}-1\right) S D_{E}^{2}+\left(N_{C}-1\right) S D_{C}{ }^{2}}{N_{E}+N_{C}-2}}
$$


Unbiased estimate of $d \approx$ calculated value of $d \times\left(1-\frac{3}{\left\{4\left(N_{E}+N_{C}\right)-9\right\}}\right)$

\section{Equation Panel: Calculation of Cohen's d values}

We used meta-analysis software to calculate mean group differences and to analyze heterogeneity (27). We interpreted effect sizes $d$ according to established guidelines (26) ( $d=0.20$, small; $d=0.50$, moderate; $d=0.80$, large) and presented them with confidence intervals. We investigated publication bias using the failsafe method (28), which shows how many studies would be needed to reduce the mean effect size down to $d=0.2$ (a robust fail safe number is described as $5 n+10$ ) (29). We also created a funnel plot by plotting effect sizes for all dependent variables against standard error, thought to be the most effective measure associated with study size. A trend towards increasing effect sizes with large standard errors would suggest that there is over-representation of statistically significant studies with small samples that have correspondingly overinflated effect sizes. We confirmed asymmetry with Egger's test (30) which evaluates whether the regression line for effect size/standard error on 1/standard error goes through the point of origin.

A significantly large amount of variation due to systematic factors indicates that effect sizes are not drawn from a common population of effect sizes and may instead be due to particular features of the study (moderators). We conducted homogeneity testing using several indicators of heterogeneity to determine whether or not moderators should be considered (27): a) a significant $Q$ statistic (the sum of squared differences between individual study effects and the pooled effect across studies) with $n-1$ degrees of freedom; b) where at least 25 per cent of the observed variance is unexplained by sampling error; and c) the $I^{2}$ statistic describing the percentage of variation across studies due to heterogeneity rather than chance.

Where heterogeneity was found and thus likely to be attributable to unique differences in the set of population effect sizes, we planned to run a random-effects weighted multiple regression (metaregression) analysis using study quality, $I Q$, duration of epilepsy and medication status as potential predictors of effect size using SPSS scripts (31).

\section{Results}

\section{Study characteristics}

An initial search yielded 1360 articles, which reduced to 1337 after examination of the abstract. Of these, 21 studies were initially identified as suitable for the meta-analysis. However, three of these studies were eliminated because the effect sizes associated with cognitive impulsivity that were 
reported in these articles were duplicated (5, 32-34); two other studies that did not use the Stroop Task were eliminated to preserve homogeneity $(35,36)$. Sixteen studies were therefore included in the analysis of response inhibition (see Table 1).

$$
<<\text { Insert Table } 1 \text { here >> }
$$

\section{Moderators}

One study did not include a comparison group (study ID 12). The mean age of the patient samples ranged from 15 to 36 years old. Most studies were matched for age with the exception of one where age was a covariate in the analysis and the effect size extracted was based upon adjusted scores (study ID 2). Several studies did not match for gender (study ID 2, 3, 5 and 8) and studies varied in the ratio of males to females in their JME group ranging from 15\% to 65\%. The mean IQ of patients ranged from 1SD either side of the mean in all samples but, in one study, the mean IQ was 2SD above average (study ID 13) and, in another, the control sample had a significantly higher IQ (study ID 16). Although mean age of seizure onset was not stated in six studies, duration of epilepsy ranged from eight to 252 months and was reported in all but three of the studies. Although seizure frequency is a potential moderator, only three studies reported data on this and details of how this information is considered is dealt with in Table 2: one study reported mean seizure frequency of 4.5 but the range of these frequencies was 0-18 (37) (study ID 4); another study reports mean seizures of 2.74 (38) (study ID 9) and finally, Thomas et al, (39) report that $50 \%$ of their sample experienced daily seizures (study ID 12). Since so few studies reported this variable seizure frequency could not be used as a potential moderator. Studies also varied in the percentage of patients who were on polytherapy, ranging from 0 to $53 \%$ (two studies did not provide any information regarding medication status (study ID 1, 5 and 15). Studies ranged in their quality as measured by the Newcastle-Ottawa Scale from three to eight stars. Based upon these study differences, we identified six potential moderators to help explain possible heterogeneity in effect sizes: quality of the study, mean age and IQ and percentage of males in the patient sample, mean duration of JME and percentage of patients on polytherapy.

$<<$ Insert Table 2 here $>$

\section{Meta-analysis of effect sizes}

We carried out a meta-analysis for cognitive measures using a random-effects model to test for overall effect size and heterogeneity. The mean effect sizes and heterogeneity indicators for each 
dependent variable are shown in Table 3 below. Cohen's $d$ is $0.50(95 \% \mathrm{Cl} 0.37-0.63 ; z=7.60$; $p=<0.0001$ ) for cognitive impulsivity. A Forest plot is shown in Figure 1.

\author{
$<<$ Insert Figure 1 here >>
}

\title{
Publication Bias
}

We explored publication bias using the fail-safe method (40): The number of non-significant papers needed to reduce the effect size associated with cognitive impulsivity differences to $d=0.2$ is estimated to be 24 , which is less than $95(5 n+10)(29)$ and suggests that publication bias is likely to be present. We produced a funnel plot (Figure 2) where effect sizes describing differences in response inhibition are plotted against standard error: this funnel plot demonstrated some asymmetry and an Egger's test confirmed this (intercept=.72, standard error $=0.30, p=0.03,95 \%$ $\mathrm{Cl}=.087-1.35$ ) suggesting that publication is biased towards larger, significant studies.

$<<$ Insert Figure 2 here $>$

\section{Regression Analysis}

Although the indicators within the cognitive impulsivity effect size analysis suggested homogeneity, we ran a random-effects weighted meta-regression analysis to explore whether predictor variables were associated with degree of effect. Six potential continuous variables were considered for metaregression but we found that mean age $(B=-.001, p=.69) ; \mathrm{IQ}(B=-.006, p=.405)$, sex ratio $(B=.003$; $p=.657)$, mean duration of JME $(B=.0001 ; p=.657)$ and percentage of patients on polytherapy $(B=-$ $.005 ; p=.231)$ quality of the study (Newcastle-Ottawa score) $(B=-.021 ; p=.69)$ were all nonsignificant moderators.

\section{Discussion}

Although Janz coined the original term "impulsive petit mal" to designate a minor seizure in which the shock-like jerks of the upper extremities were described as "impulsions" rather than true myoclonic jerks, the term "impulsive" appears thoroughly appropriate to describe the neurocognitive aspect of JME. This meta-analysis shows a moderately strong association between JME and cognitive impulsivity $(d=0.5)$ with no indication of heterogeneity. This supports the hypothesis that response inhibition, a component of cognitive impulsivity, is consistently impaired in JME. The effect size is similar to that seen for executive function in general (0.72) (41) and suggests that analysis narrowing the diversity of processes and measures for EF is responsible for minimising heterogeneity of association. We did not find any evidence for the influence of any available moderators we applied but we note that the lack of information on seizure frequency in many of the 
studies is a limitation: seizure frequency may be an important indicator of severity helping to explain the presence of cognitive impulsivity. The results are also consistent with neuroimaging evidence for overlapping networks involved in EF and in seizure generation in JME $(37,42)$. Our meta-analysis is restricted by possible publication bias because small studies with non-significant findings are less likely to be published and so the mean effect size for response inhibition might possibly be smaller. Access to original data or a prospective study would allow a better evaluation of potential predictors.

\section{Prognostic Biomarkers and Endophenotypes}

The consistent association of cognitive impulsivity with JME has implications for both the development of comorbidities, psychosocial outcomes and treatment adherence. The long term prognosis of JME is surprisingly poor according to two population-based studies $(43,44)$ and the possibility that such outcomes are mediated by EF deficits such as impulsivity is worthy of longitudinal investigation. Two small longitudinal studies suggest that personality traits are important predictive factors for long-term socio-economic and psychiatric prognosis in epilepsy (43, 45) but more definitive unbiased prospective studies are required to provide better quality evidence. If true though, a simple screening test or rating scale for impulsivity at diagnosis might potentially be a valuable biomarker to stratify at-risk patients who could benefit from preventive psychosocial intervention.

Dysexecutive function has previously been suggested as an endophenotype in JME in a small comparison of patients, siblings and controls when behavior was rated by a person known to the participant (46). The use of endophenotypes has also been advocated to significantly enhance the power for gene discovery in complex disorders and measures of EF or impulsivity could certainly serve this purpose in JME and be used to test shared aetiology with other neurodevelopmental or neuropsychiatric traits (47). EF interventions are also in use for teenagers and young adults with a variety of neuropsychiatric disorders (48).

\section{Cognitive impulsivity and JME}

Cognitive impulsivity includes both response inhibition and decision-making. The Stroop task is an effective analogue for this process since it requires a degree of inhibition to facilitate the overriding of an automatic response; decision making is also required to apply a new rule. Three studies in JME show impaired decision making compared to controls (49-51). Neuropsychological and neuroimaging endophenotypes have both been described in $\operatorname{GGE}(52,53)$ suggesting an inherited abnormality in brain network topology underlying cognitive, anatomical and seizure susceptibility traits. The primary regions involved in the performance of the Stroop Task, as identified through meta-analysis 
of $\mathrm{FMRI}$ studies, including inferior frontal gyrus, anterior cingulate and pre-SMA, regions often upregulated during conditions involving cognitive control (54) overlap with those implicated in the seizure mechanism in JME (55). Reflecting this observation is a) the analysis of white matter tracts of patients with JME revealing reduced fractional anisotropy within the SMA compared with controls, which suggests there is decreased fibre density within the pathways associated with this region (56, $57)$ and b) reduction in grey matter volume in this same region compared with controls $(37,42)$. Furthermore structural differences in the connectivity of the SMA may also be specific to JME as they were not observed in patients with frontal lobe epilepsy (56). Changes in the microstructure of this motor mesial region could possibly play a role in triggering the myoclonic seizures typical in JME. 


\section{Acknowledgements and Funding}

This work was supported by grants from the Canadian Institutes of Health Research: Biology of Juvenile Myoclonic Epilepsy (BIOJUME) (201503MOP-342469, DKP); European Union Programme of the Seventh Framework: Development of Strategies for Innovative Research to improve diagnosis, prevention and treatment in children with difficult to treat Epilepsy, "DESIRE" (602531, DKP); National Institute for Health Research Programme Grant for Applied Research: Changing Agendas on Sleep, Treatment and Learning in Epilepsy (CASTLE) RP-PG-0615-20007 (DKP); Medical Research Council (MRC) Centre grant (MR/N026063/1) (DKP); Waterloo Foundation Project Grant 164-3020 (DKP); Charles Sykes Epilepsy Research Trust (DKP); NIHR Specialist Biomedical Research Centre for Mental Health of South London and Maudsley NHS Foundation Trust (DKP). 


\section{References}

1. Janz D. Epilepsy with impulsive petit mal (juvenile myoclonic epilepsy). Acta Neurol Scand. 1985;72(5):449-59.

2. de Araujo Filho GM, Pascalicchio TF, Sousa Pda S, Lin K, Ferreira Guilhoto LM, Yacubian EM. Psychiatric disorders in juvenile myoclonic epilepsy: a controlled study of 100 patients. Epilepsy Behav. 2007;10(3):437-41.

3. Trinka E, Kienpointner G, Unterberger I, Luef G, Bauer G, Doering LB, et al. Psychiatric comorbidity in juvenile myoclonic epilepsy. Epilepsia. 2006;47(12):2086-91.

4. Rzezak P, Moschetta SP, Lima E, Castro CX, Vincentiis S, Coan AC, et al. Distinct domains of impulsivity are impaired in juvenile myoclonic epilepsy but not in temporal lobe epilepsy. Epilepsy Behav. 2015;45:44-8.

5. Valente KD, Rzezak P, Moschetta SP, de Vincentiis S, Coan AC, Guerreiro CA. Delineating behavioral and cognitive phenotypes in juvenile myoclonic epilepsy: Are we missing the forest for the trees? Epilepsy Behav. 2016;54:95-9.

6. Cao B, Tang Y, Li J, Zhang X, Shang H-F, Zhou D. A meta-analysis of voxel-based morphometry studies on gray matter volume alteration in juvenile myoclonic epilepsy. Epilepsy Res. 2013;106(3):370-7.

7. Haber SN, Calzavara R. The cortico-basal ganglia integrative network: the role of the thalamus. Brain Res Bull. 2009;78(2):69-74.

8. Wandschneider B, Thompson PJ, Vollmar C, Koepp MJ. Frontal lobe function and structure in juvenile myoclonic epilepsy: a comprehensive review of neuropsychological and imaging data. Epilepsia. 2012;53(12):2091-8.

9. Hoie B, Sommerfelt K, Waaler PE, Alsaker FD, Skeidsvoll H, Mykletun A. The combined burden of cognitive, executive function, and psychosocial problems in children with epilepsy: a population-based study. Dev Med Child Neurol. 2008;50(7):530-6. 
10. Jackson DC, Dabbs K, Walker NM, Jones JE, Hsu DA, Stafstrom CE, et al. The neuropsychological and academic substrate of new/recent-onset epilepsies. J Pediatr. 2013;162(5):1047-53 e1.

11. Miyake A, Friedman NP. The Nature and Organization of Individual Differences in Executive Functions: Four General Conclusions. Curr Dir Psychol Sci. 2012;21(1):8-14.

12. Jurado MB, Rosselli M. The elusive nature of executive functions: a review of our current understanding. Neuropsychol Rev. 2007;17(3):213-33.

13. Aytaclar S, Tarter RE, Kirisci L, Lu S. Association between hyperactivity and executive cognitive functioning in childhood and substance use in early adolescence. J Am Acad Child Adolesc Psychiatry. 1999;38(2):172-8.

14. Nigg JT, Wong MM, Martel MM, Jester JM, Puttler LI, Glass JM, et al. Poor response inhibition as a predictor of problem drinking and illicit drug use in adolescents at risk for alcoholism and other substance use disorders. J Am Acad Child Adolesc Psychiatry. 2006;45(4):468-75. 15. Stautz K, Pechey R, Couturier DL, Deary IJ, Marteau TM. Do Executive Function and Impulsivity Predict Adolescent Health Behaviour after Accounting for Intelligence? Findings from the ALSPAC Cohort. PLoS One. 2016;11(8):e0160512.

16. Duke DC, Harris MA. Executive function, adherence, and glycemic control in adolescents with type 1 diabetes: a literature review. Curr Diab Rep. 2014;14(10):532.

17. Loughman A, Bowden S, D'souza W. Cognitive functioning in idiopathic generalised epilepsies: a systematic review and meta-analysis. Neurosci Biobehav Rev. 2014;43:20-34. 18. Chamberlain SR, Sahakian BJ. The neuropsychiatry of impulsivity. Curr Opin Psych. 2007;20(3):255-61.

19. Camfield CS, Camfield PR. Juvenile myoclonic epilepsy 25 years after seizure onset A population-based study. Neurology. 2009;73(13):1041-5. 
20. Schneider-von Podewils F, Gasse C, Geithner J, Wang ZI, Bombach P, Berneiser J, et al. Clinical predictors of the long-term social outcome and quality of life in juvenile myoclonic epilepsy: 20-65 years of follow-up. Epilepsia. 2014;55(2):322-30.

21. Holtkamp $M$, Senf $P$, Kirschbaum A, Janz D. Psychosocial long-term outcome in juvenile myoclonic epilepsy. Epilepsia. 2014;55(11):1732-8.

22. Craig F, Margari F, Legrottaglie AR, Palumbi R, de Giambattista C, Margari L. A review of executive function deficits in autism spectrum disorder and attention-deficit/hyperactivity disorder. Neuropsychiatr Dis Treat. 2016;12:1191-202.

23. Stroup DF, Berlin JA, Morton SC, Olkin I, Williamson GD, Rennie D, et al. Meta-analysis of observational studies in epidemiology: a proposal for reporting. JAMA. 2000;283(15):2008-12.

24. Wells G, Shea B, O'connell D, Peterson J, Welch V, Losos M, et al. The Newcastle-Ottawa Scale (NOS) for assessing the quality of nonrandomised studies in meta-analyses. Ottawa Hospital Research Institute, 2014. oxford. ASp; 2015.

25. Trenité DGK-N, Schmitz B, Janz D, Delgado-Escueta AV, Thomas P, Hirsch E, et al. Consensus on diagnosis and management of JME: from founder's observations to current trends. Epilepsy Behav. 2013;28:S87-S90.

26. Cohen J. Statistical power analysis for the behavioral sciences. New York: Erlbaum; 1988.

27. Schwarzer R. Meta-analysis software. 5.3 ed. Dubuque, IA: Brown Publishers; 1991.

28. Hunter JE, Schmidt FL, Jackson GB. Meta-analysis: cumulating research findings across studies. Beverly Hills, CA: Sage; 1982.

29. Rosenberg MS. The file-drawer problem revisited: a general weighted method for calculating fail-safe numbers in meta-analysis. Evolution. 2005;59(2):464-8.

30. Sterne JA, Egger M. Funnel plots for detecting bias in meta-analysis: guidelines on choice of axis. J Clin Epidemiol. 2001;54(10):1046-55.

31. Wilson DB, Lipsey M. Practical meta-analysis 2001 [ 
32. Moschetta S, Valente KD. Impulsivity and seizure frequency, but not cognitive deficits, impact social adjustment in patients with juvenile myoclonic epilepsy. Epilepsia. 2013;54(5):866-70. 33. Pulsipher DT, Seidenberg M, Guidotti L, Tuchscherer VN, Morton J, Sheth RD, et al. Thalamofrontal circuitry and executive dysfunction in recent-onset juvenile myoclonic epilepsy. Epilepsia. 2009;50(5):1210-9.

34. Moschetta SP, Valente KD. Juvenile myoclonic epilepsy: the impact of clinical variables and psychiatric disorders on executive profile assessed with a comprehensive neuropsychological battery. Epilepsy Behav. 2012;25(4):682-6.

35. Piazzini A, Turner K, Vignoli A, Canger R, Canevini MP. Frontal cognitive dysfunction in juvenile myoclonic epilepsy. Epilepsia. 2008;49(4):657-62.

36. O'Muircheartaigh J, Vollmar C, Barker G, Kumari V, Symms M, Thompson P, et al. Focal structural changes and cognitive dysfunction in juvenile myoclonic epilepsy. Neurology. 2011;76(1):34-40.

37. Kim JH, Suh SI, Park SY, Seo WK, Koh I, Koh SB, et al. Microstructural white matter abnormality and frontal cognitive dysfunctions in juvenile myoclonic epilepsy. Epilepsia. 2012;53(8):1371-8.

38. Pascalicchio TF, de Araujo Filho GM, da Silva Noffs MH, Lin K, Caboclo LO, Vidal-Dourado M, et al. Neuropsychological profile of patients with juvenile myoclonic epilepsy: a controlled study of 50 patients. Epilepsy Behav. 2007;10(2):263-7.

39. Thomas RH, Walsh J, Church C, Sills GJ, Marson AG, Baker GA, et al. A comprehensive neuropsychological description of cognition in drug-refractory juvenile myoclonic epilepsy. Epilepsy Behav. 2014;36:124-9.

40. Orwin RG. A fail-safe $\mathrm{N}$ for effect size in meta-analysis. Journal of educational statistics. $1983 ; 8(2): 157-9$.

41. Loughman A, Bowden SC, D'Souza WJ. A comprehensive assessment of cognitive function in the common genetic generalized epilepsy syndromes. Eur J Neurol. 2017;24(3):453-60. 
42. O'Muircheartaigh J, Vollmar C, Barker GJ, Kumari V, Symms MR, Thompson P, et al. Focal structural changes and cognitive dysfunction in juvenile myoclonic epilepsy. Neurology. 2011;76(1):34-40.

43. Camfield CS, Camfield PR. Juvenile myoclonic epilepsy 25 years after seizure onset: a population-based study. Neurology. 2009;73(13):1041-5.

44. Syvertsen M, Selmer K, Enger U, Nakken KO, Pal DK, Smith A, et al. Psychosocial complications in juvenile myoclonic epilepsy. Epilepsy Behav. 2019;90:122-8.

45. Lund $\mathrm{M}$, Reintoft $\mathrm{H}$, Simonsen $\mathrm{N}$. [A controlled sociological and psychological study on patients with juvenile myoclonus epilepsy]. Nervenarzt. 1976;47(12):708-12.

46. Iqbal N, Caswell H, Muir R, Cadden A, Ferguson S, Mackenzie H, et al. Neuropsychological profiles of patients with juvenile myoclonic epilepsy and their siblings: An extended study. Epilepsia. 2015;56(8):1301-8.

47. Glahn DC, Knowles EE, McKay DR, Sprooten E, Raventos H, Blangero J, et al. Arguments for the sake of endophenotypes: examining common misconceptions about the use of endophenotypes in psychiatric genetics. Am J Med Genet B Neuropsychiatr Genet. 2014;165B(2):122-30.

48. Otero TM, Barker LA, Naglieri JA. Executive function treatment and intervention in schools. Appl Neuropsychol Child. 2014;3(3):205-14.

49. Zamarian L, Hofler J, Kuchukhidze G, Delazer M, Bonatti E, Kemmler G, et al. Decision making in juvenile myoclonic epilepsy. J Neurol. 2013;260(3):839-46.

50. Unterberger I, Zamarian L, Prieschl M, Bergmann M, Walser G, Luef G, et al. Risky Decision Making in Juvenile Myoclonic Epilepsy. Front Neurol. 2018;9:195.

51. Wandschneider B, Centeno M, Vollmar C, Stretton J, O'Muircheartaigh J, Thompson PJ, et al. Risk-taking behavior in juvenile myoclonic epilepsy. Epilepsia. 2013;54(12):2158-65.

52. Chowdhury FA, Elwes RD, Koutroumanidis M, Morris RG, Nashef L, Richardson MP. Impaired cognitive function in idiopathic generalized epilepsy and unaffected family members: an epilepsy endophenotype. Epilepsia. 2014;55(6):835-40. 
53. Chowdhury FA, Woldman W, FitzGerald TH, Elwes RD, Nashef L, Terry JR, et al. Revealing a brain network endophenotype in families with idiopathic generalised epilepsy. PLoS One. 2014;9(10):e110136.

54. Derrfuss J, Brass M, Neumann J, von Cramon DY. Involvement of the inferior frontal junction in cognitive control: Meta-analyses of switching and Stroop studies. Hum Brain Mapp. $2005 ; 25(1): 22-34$.

55. Vollmar C, O'muircheartaigh J, Symms M, Barker G, Thompson P, Kumari V, et al. Altered microstructural connectivity in juvenile myoclonic epilepsy the missing link. Neurology. 2012;78(20):1555-9.

56. Vulliemoz S, Vollmar C, Koepp MJ, Yogarajah M, O'muircheartaigh J, Carmichael DW, et al. Connectivity of the supplementary motor area in juvenile myoclonic epilepsy and frontal lobe epilepsy. Epilepsia. 2011;52(3):507-14.

57. Ekmekci B, Bulut HT, Gümüştaş F, Yıldırım A, Kuştepe A. The relationship between white matter abnormalities and cognitive functions in new-onset juvenile myoclonic epilepsy. Epilepsy Behav. 2016;62:166-70.

58. Gelziniene G, Jurkeviciene G, Marmiene V, Adomaitiene V, Endziniene M. Executive functions in adolescents with idiopathic generalized epilepsy. Medicina (Kaunas). 2011;47(6):313-9. 59. Iqbal N, Caswell HL, Hare DJ, Pilkington O, Mercer S, Duncan S. Neuropsychological profiles of patients with juvenile myoclonic epilepsy and their siblings: a preliminary controlled experimental video-EEG case series. Epilepsy Behav. 2009;14(3):516-21.

60. Levav M, Mirsky AF, Herault J, Xiong L, Amir N, Andermann E. Familial association of neuropsychological traits in patients with generalized and partial seizure disorders. J Clin Exp Neuropsychol. 2002;24(3):311-26.

61. Lin JJ, Dabbs K, Riley JD, Jones JE, Jackson DC, Hsu DA, et al. Neurodevelopment in newonset juvenile myoclonic epilepsy over the first 2 years. Ann Neurol. 2014;76(5):660-8. 
62. Moschetta SP, Valente KD. Juvenile myoclonic epilepsy: the impact of clinical variables and psychiatric disorders on executive profile assessed with a comprehensive neuropsychological battery. Epilepsy Behav. 2012;25(4):682-6.

63. Motamedi M, Nasergivehch S, Karamghadiri N, Noroozian M. Juvenile Myoclonic Epilepsy (JME): Neuropsychological Profile and Related Factors with Cognitive Dysfunction. Iran J Psychiatry. 2014;9(1):14-9.

64. Roebling R, Scheerer N, Uttner I, Gruber O, Kraft E, Lerche H. Evaluation of cognition, structural, and functional MRI in juvenile myoclonic epilepsy. Epilepsia. 2009;50(11):2456-65.

65. Sonmez F, Atakli D, Sari H, Atay T, Arpaci B. Cognitive function in juvenile myoclonic epilepsy. Epilepsy Behav. 2004;5(3):329-36.

66. Wandschneider B, Kopp UA, Kliegel M, Stephani U, Kurlemann G, Janz D, et al. Prospective memory in patients with juvenile myoclonic epilepsy and their healthy siblings. Neurology. 2010;75(24):2161-7.

67. Cevik N, Koksal A, Dogan VB, Dirican AC, Bayramoglu S, Ozturk M, et al. Evaluation of cognitive functions of juvenile myoclonic epileptic patients by magnetic resonance spectroscopy and neuropsychiatric cognitive tests concurrently. Neurol Sci. 2016;37(4):623-7.

68. Abarrategui B, Parejo-Carbonell B, Garcia Garcia ME, Di Capua D, Garcia-Morales I. The cognitive phenotype of idiopathic generalized epilepsy. Epilepsy Behav. 2018;89:99-104. 


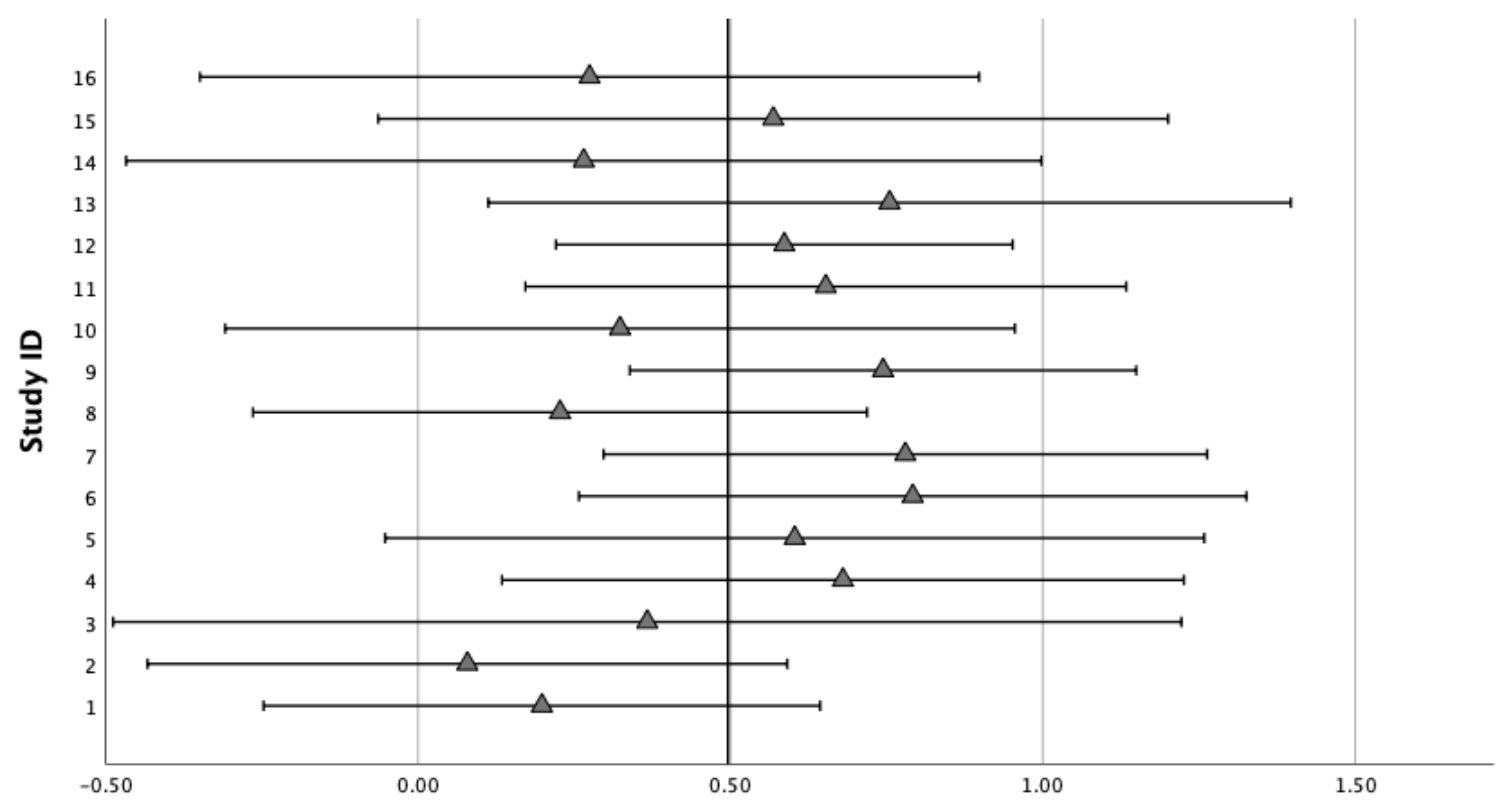

Effect Size and 95\% confidence intervals

Figure 1: Forest Plot to show effect sizes (Cohen's d) for cognitive impulsivity studies 


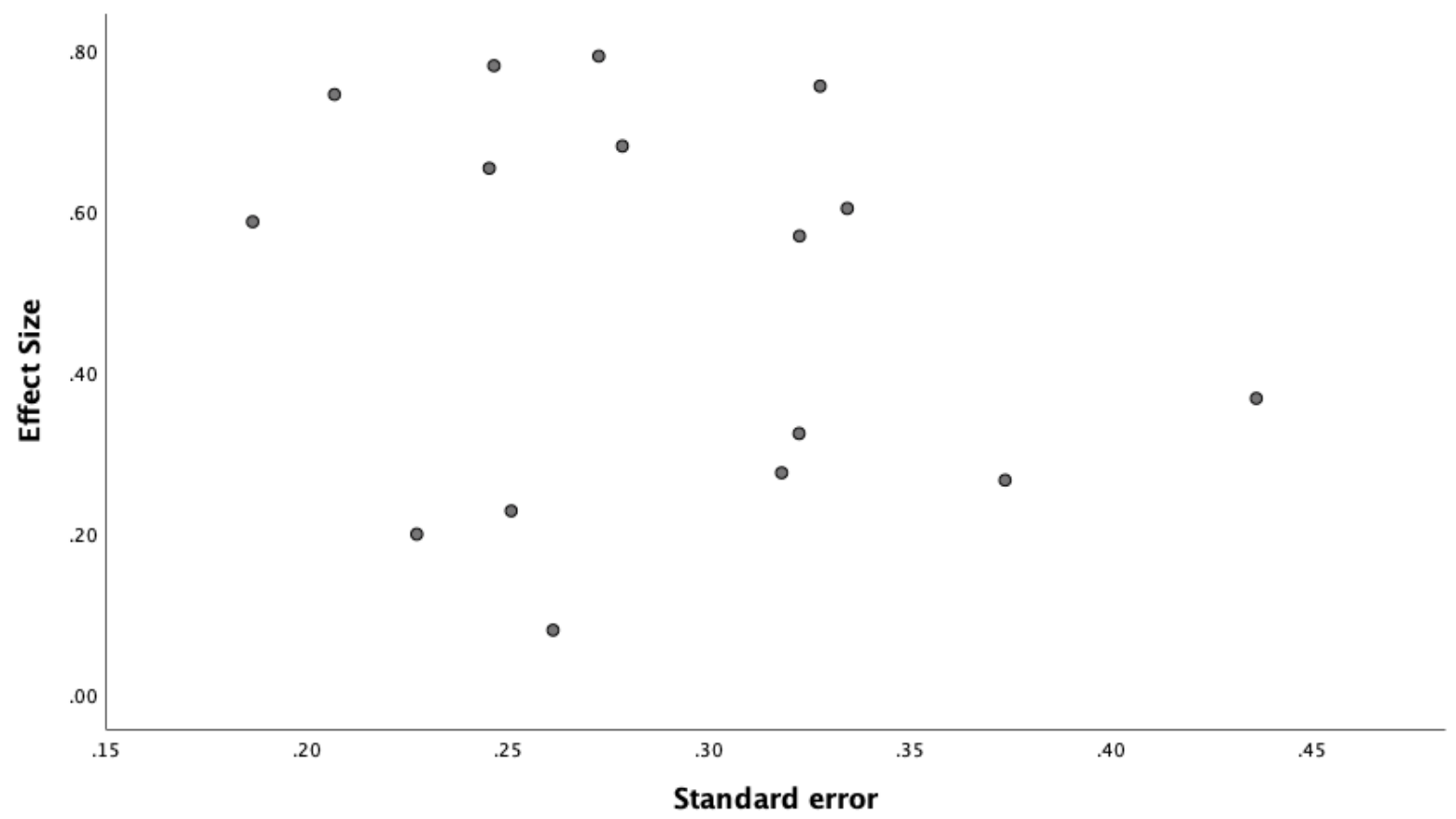

Figure 2: Funnel plot shows bias towards studies with smaller standard errors where greater effect sizes are observed 


\begin{tabular}{|c|c|c|c|c|c|c|c|c|c|c|c|c|c|}
\hline Study ID & First Author & $\begin{array}{l}\text { Publication } \\
\text { year }\end{array}$ & $\begin{array}{l}\text { Sample } \\
\text { size: } \\
\text { Controls } \\
\text { v JME }\end{array}$ & $\begin{array}{l}\text { Age } \\
\text { (years): } \\
\text { Controls v } \\
\text { JME }\end{array}$ & $\begin{array}{l}\text { IQ: Controls v } \\
\text { JME }\end{array}$ & $\begin{array}{c}\text { Gender } \\
\text { (\% male): } \\
\text { Controls } \\
\text { v JME }\end{array}$ & $\begin{array}{l}\text { Education (years): } \\
\text { Controls v JME }\end{array}$ & $\begin{array}{l}\text { Medication } \\
\text { (\%): none v } \\
\text { mono v } \\
\text { poly }\end{array}$ & $\begin{array}{l}\text { VPA }(\%) \text { and dose where } \\
\text { reported }\end{array}$ & $\begin{array}{l}\text { Mean } \\
\text { Age of } \\
\text { onset } \\
\text { (years) }\end{array}$ & $\begin{array}{c}\text { Mean } \\
\text { Duration } \\
\text { (months) }\end{array}$ & $\begin{array}{l}\text { Quality } \\
\text { Score } \\
\text { (Newcastle } \\
\text { and } \\
\text { Ottowa) }\end{array}$ & $\begin{array}{l}\text { Effect size } \\
\text { for } \\
\text { inhibition of } \\
\text { interference } \\
\text { (d) }\end{array}$ \\
\hline 1 & Gelziniene (58) & 2011 & $59 \vee 29$ & $15.5 / 15.5$ & not stated & $39 \vee 39$ & $9.0 \vee 9.4$ & not stated & not stated & 13.6 & 14 & 6 & 0.2 \\
\hline 2 & Iqbal (46) & 2015 & $44 \vee 22$ & $25.7 / 26.7$ & 109 v 101 & $48 \vee 32$ & 14.6 v 14.6 & $0 \vee 78 v 22$ & 59 & not stated & not stated & 7 & 0.08 \\
\hline 3 & Iqbal (59) & 2009 & $16 \vee 8$ & $28.7 / 28.1$ & $110 \vee 98$ & $50 \vee 38$ & 16.2 v 15.3 & $0 \vee 87 v 13$ & 87 & not stated & not stated & 7 & 0.38 \\
\hline 4 & $\operatorname{Kim}(37)$ & 2012 & $30 \vee 25$ & $25.5 \vee 25.3$ & not stated & $43 \vee 40$ & 14.5 v 14.4 & $0 \vee 88 v 12$ & 80 & 14.7 & 127 & 6 & 0.69 \\
\hline 5 & Levav (60) & 2002 & $55 \vee 11$ & $26.0 \vee 36.8$ & no diff & $45 \vee 18$ & 12.2 v 11.7 & $9 \vee 73 \vee 18$ & not stated & 15.9 & 251 & 6 & 0.61 \\
\hline 6 & $\operatorname{Lin}(61)$ & 2014 & $57 \vee 19$ & 12.6 v 14.9 & 110 v 111 & $47 \vee 47$ & All still at school & $37 \vee 58 \vee 5$ & 42 & 14 & 8.4 & 8 & 0.8 \\
\hline 7 & Moschetta (62) & 2012 & $42 \vee 42$ & $26.6 \vee 26.6$ & not stated v 91.5 & $47 \vee 47$ & 10.0 v 10.0 & $0 \vee 100 \vee 0$ & 98 & 14 & 214 & 3 & 0.79 \\
\hline 8 & Motamedi (63) & 2014 & $32 \vee 32$ & $33.7 \vee 28.7$ & 116 v 107 & $53 \vee 41$ & $\begin{array}{c}\text { not stated but } 50 \% \mathrm{v} \\
50 \% \text { (graduates) }\end{array}$ & $0 \vee 69 \vee 31$ & Exact proportions not stated & not stated & 142 & 7 & 0.23 \\
\hline 9 & Pascalicchio (38) & 2007 & $50 \vee 50$ & $26.3 \vee 26.2$ & $100 \vee 91$ & $50 \vee 50$ & $10.9 \vee 10.8$ & $0 \vee 100 \vee 0$ & 100 & not stated & 166 & 7 & 0.75 \\
\hline 10 & Roebling (64) & 2009 & $20 \vee 19$ & $24.4 \vee 24.2$ & not stated & $20 v 15$ & not stated & $16 \vee 68 \vee 16$ & 52 & not stated & not stated & 8 & 0.33 \\
\hline 11 & Sonmez (65) & 2004 & $35 \vee 35$ & $22.7 \vee 21.7$ & $95 \vee 91$ & $34 \vee 29$ & $14 \%$ v $11 \%$ (graduates) & $0 \vee 100 \vee 0$ & $\begin{array}{c}83 \\
\text { Dose: } 50-100 \mathrm{lg} / \mathrm{mL}\end{array}$ & not stated & 86 & 8 & 0.66 \\
\hline 12 & Thomas (39) & 2014 & 60 & 31 & 89.3 & 25 & 13 & $0 v 47 v 53$ & $\begin{array}{l}\text { Exact proportions not stated } \\
\text { mean daily dose of } 1464 \mathrm{mg}\end{array}$ & 12 & 252 & 7 & 0.59 \\
\hline 13 & Wandschneider (66) & 2010 & $21 \vee 19$ & $25.2 \vee 25.5$ & $98 \vee 128$ & $48 \vee 26$ & 11.5 v 11.5 & $16 \vee 58 \vee 26$ & 58 & 14.5 & 133 & 8 & 0.77 \\
\hline 14 & Chowdhury (52) & 2014 & $36 \vee 9$ & $30.0 \vee 32.0$ & 116 v 104 & $49 \vee 44$ & not stated & $12 \vee 44 \vee 44$ & $\begin{array}{c}55 \\
\text { Dose Information not complete }\end{array}$ & 14.5 & 204 & 6 & 0.27 \\
\hline 15 & Cevik (67) & 2016 & $20 \vee 20$ & $26.3 \vee 26.9$ & not stated & not stated & 9.06 v 8.55 & not stated & not stated & 15 & 143 & 5 & 0.58 \\
\hline 16 & Abarrategui (68) & 2018 & $21 \vee 19$ & $33 \vee 33$ & $110 \vee 99$ & $52 \vee 52$ & 14 v 14 & not stated & $\begin{array}{c}50 \% \\
\text { Dose: } 950 \mathrm{mg}\end{array}$ & 14 & 216 & 7 & 0.28 \\
\hline
\end{tabular}

Table 1: Moderators and outcome variables reported within individual studies included in the meta-analysis 


\begin{tabular}{|c|c|}
\hline ID Number & Details of seizures and diagnosis of JME where available for each manuscript \\
\hline 1 & $\begin{array}{l}\text { Sample comprised of either active myoclonias (55\%) where jerks have occurred within past three months and for at least } 3 \text { days a week and or } \\
\text { inactive myoclonias where the above was not the case }(45 \%) \text {. Frequency data not provided }\end{array}$ \\
\hline 2 & Sample 'satisfied the diagnostic criteria for JME' but no frequency data provided \\
\hline 3 & Sample 'met the diagnostic criteria for JME' but no frequency data provided \\
\hline 4 & $\begin{array}{l}\text { Myoclonic jerks were present in all patients: unequivocal seizure semiology of JME-myoclonic seizure involving the bilateral upper extremities } \\
\text { exclusively or preferentially occurring early in the morning, with or without GTCS or absence seizure: GCTS frequency is tabulated and is } 4.5 \text { (4.7) per } \\
3 \text { years. }\end{array}$ \\
\hline 5 & Diagnoses were made by a qualified neurologist. No frequency data is provided. \\
\hline 6 & $\begin{array}{l}\text { Diagnoses were made by a qualified pediatric neurologist. JME diagnosed according to the international classification of epilepsy on the basis of a } \\
\text { history of myoclonic jerks, with or without generalized tonic-clonic seizures (GTCS). No frequency data was provided }\end{array}$ \\
\hline 7 & $\begin{array}{l}\text { Patients were required to have an unequivocal diagnosis of JME, according to the International League Against Epilepsy proposal for syndrome } \\
\text { classification but no details about myoclonus were provided. No frequency data was provided. }\end{array}$ \\
\hline 8 & $\begin{array}{l}\text { JME diagnoses and EEG recordings were carried out by an expert neurologist in the field of Epilepsy. JME was diagnosed using International League } \\
\text { Against Epilepsy (ILAE) classification. No frequency data is provided }\end{array}$ \\
\hline 9 & $\begin{array}{l}\text { Patients were electroclinically diagnosed with JME based on ILAE classification. The mean number of GTCS was } 1.38 \text {, and the mean number of } \\
\text { myoclonic seizures was } 2.74 \text {. }\end{array}$ \\
\hline 10 & $\begin{array}{l}\text { All patients reported bilateral myoclonic jerks occur- ring exclusively or preferentially after awakening. Four patients experienced at least one } \\
\text { generalized tonic-clonic seizure (GTCS), which also occurred during the morning after awakening. The interictal EEGs showed generalized } \\
\text { polypspikes or spike-wave discharges in all patients. The diagnosis of JME was based on history and typical EEG findings on a } 1.5 \text { Tesla scanner and } \\
\text { was confirmed by experienced neurologists and epileptologists. No frequency data is provided. }\end{array}$ \\
\hline 11 & Diagnosis was made using clinical and electroencephalo- graphic features. No frequency data is provided. \\
\hline 12 & $\begin{array}{l}\text { Seizure frequency was measured using diaries and two-thirds returned seizure diaries; half reported daily myoclonus that persisted (only } 7.5 \% \\
\text { reported abatement of these seizures). }\end{array}$ \\
\hline 13 & $\begin{array}{l}\text { The diagnosis of JME was based on the history and typical EEG findings and the absence of pathologies in brain imaging. No frequency data is } \\
\text { provided. }\end{array}$ \\
\hline 14 & $\begin{array}{l}\text { The epilepsy syndrome was determined by experi- enced epileptologists on the basis of clinical history, imaging, and EEG findings according to } \\
\text { International League Against Epilepsy (ILAE) } 1989 \text { classification of epilepsies. No frequency data is provided. }\end{array}$ \\
\hline 15 & No detail given about diagnosis of JME \\
\hline 16 & $\begin{array}{l}\text { Diagnosis and syndromic classification were based on clinical history and EEG findings according to the International League Against Ep- ilepsy (ILAE). } \\
\text { No frequency data is provided. }\end{array}$ \\
\hline
\end{tabular}




\begin{tabular}{|l|c|}
\hline Variable & Response inhibition \\
\hline Mean effect size & 0.50 \\
\hline $\mathrm{N}$ (number of studies) & $1047(16)$ \\
\hline $\mathrm{z}(\mathrm{p})$ & $7.60(<.0001)$ \\
\hline Residual variance & 0.086 \\
\hline Homogeneity Q (p) & $13.2(0.59)$ \\
\hline \% variance unexplained by sampling error: $>25 \%$ & $<1 \%$ \\
\hline indicates heterogeneity & $>99 \%$ \\
\hline 2\% & \\
\hline
\end{tabular}

Table 3: Mean effect sizes, $N, z$ and measures to evaluate heterogeneity of the mean effect size 